\title{
PENENTUAN UMUR SIMPAN DODOL KACANG MERAH MENGGUNAKAN METODE ACCELERATED SHELF LIFE TEST (ASLT) MODEL ARRHENIUS
}

\section{Determination of Shelf Life Red Bean Dodol Using the Method of Accelerated Shelf Life Test (ASLT) Arrhenius Model}

Ghina Anzalina, D. L. Rahayu

Program Studi Pendidikan Teknologi Agroindustri, Fakultas Pendidikan Teknologi dan Kejuruan Universitas Pendidikan Indonesia, Bandung, Indonesia

E-mail: ghinaanzalina@student.upi.edu

\begin{abstract}
ABSTRAK
Dodol merupakan salah satu makanan kudapan tradisional yang cukup digemari oleh masyarakat Indonesia. Terdapat beragam jenis dodol, salah satunya yakni dodol kacang merah yang diproduksi oleh IRT Pusaka di daerah Cililin-Bandung Barat. Terdapat kekurangan dalam label produk dodol kacang merah IRT Pusaka yaitu belum dicantumkannya tanggal kadaluwarsa. Belum dilakukannya pengujian pendugaan umur simpan dodol kacang merah Cililin secara ilmiah menjadi alasan belum dicantumkannya informasi saran penyimpanan dan batas tanggal masa penyimpanan yang baik untuk dikonsumsi pada label kemasan produk. Oleh karena itu penelitian ini dilakukan untuk mengetahui perkiraan umur simpan dodol kacang merah IRT Pusaka menggunakan metode Accelerated Shelf Life Test (ASLT) Model Arrhenius. Pengujian ASLT Model Arrhenius menggunakan dua faktor yaitu suhu penyimpanan $\left(25^{\circ} \mathrm{C}\right.$ dan $\left.35^{\circ} \mathrm{C}\right)$ dan waktu penyimpanan (15 hari). Dodol kacang merah disimpan dalam inkubator dan diambil setiap 3 hari hingga hari ke 15 untuk pengujian parameter mutunya. Parameter mutu yang diamati adalah analisis jumlah kapang dan analisis kimiawi kadar gula. Hasil penelitian menunjukan berdasarkan respon jumlah kapang umur simpan dodol kacang merah yang disimpan pada suhu $25^{\circ} \mathrm{C}$ dan $35^{\circ} \mathrm{C}$ berturut-turut adalah 14.27 hari dan 16.20 hari, sedangkan berdasarkan respon kadar gula umur simpan dodol kacang merah yang disimpan pada suhu $25^{\circ} \mathrm{C}$ dan $35^{\circ} \mathrm{C}$ berturut-turut adalah 15.08 hari dan 16.68 hari.
\end{abstract}

Kata kunci: $A S L T$, dodol kacang merah, umur simpan

\begin{abstract}
Dodol is one of the traditional snack foods that quite popular in Indonesian people. One kind of dodol is red bean dodol that produced by Pusaka home industry in Cililin region, West Java. There was a weakeness on the product label packaging. Pusaka home industry have not labelled the product with expired date information. Not having caried out scientific shelf life testing on its product was the reason why the expired date has not been stated. Therefore this reasearch was conducted to know the approximate shelf life of red bean dodol Pusaka home industry using Arrhenius Model Accelerated Shelf Life Test (ASLT) method. There were two factors that used in Arrhenius Model Accelerated Shelf Life Test (ASLT), namely the storage temperature factor $\left(25^{\circ} \mathrm{C}\right.$ and $\left.35^{\circ} \mathrm{C}\right)$ and time of storage (15 days). Red bean dodol were storaged in incubator and then red bean dodol samples were taken each three days until the 15th day for quality parameter observation. The quality parameters observed were number of mold and sugar content. Research results showed that based on the response of mold number, shelf life of red bean dodol stored at $25^{\circ} \mathrm{C}$ and $35^{\circ} \mathrm{C}$ respectively was 14.27 days and 16,20 days. While based on sugar content response, shelf life of red bean dodol stored at $25^{\circ} \mathrm{C}$ and $35 \mathrm{C}$ respectively was 15.08 days and 16.68 days.
\end{abstract}

Keywords: $A S L T$, red been dodol, shelf life 


\section{PENDAHULUAN}

Dodol merupakan salah satu makanan tradisional yang cukup digemari oleh masyarakat Indonesia. Menurut Nasaruddin dkk. (2012) dodol dapat digolongkan sebagai makanan ringan yang dibuat dari campuran tepung beras ketan putih, gula merah, dan santan kelapa, dididihkan hingga mengental, berminyak dan tidak lengket, dan apabila dingin pasta akan menjadi padat, kenyal dan dapat diiris. Dodol termasuk ke dalam jenis pangan semi basah yang memiliki karakteristik khas yaitu kadar air yang agak tinggi, tetapi aktivitas airnya (aw) cukup rendah, sehingga daya tahannya tidak terlalu singkat. Kadar air dodol $10-15 \%$ dan aw 0.647-0.721 (Syamsir dan Prita, 2010).

Industri dodol biasanya merupakan industri kecil atau industri rumah tangga dimana industri ini masih dilakukan secara sederhana dengan mengunakan peralatan seadanya dan dilakukan secara turun temurun. Salah satu Industri Rumah Tangga (IRT) yang memproduksi produk dodol yaitu IRT Pusaka yang berada di Cililin, Bandung Barat. Dodol yang diproduksi merupakan dodol kacang merah. Dodol kacang merah yang diproduksi oleh IRT Pusaka memiliki bentuk bulat panjang dan dikemas menggunakan kulit jagung sebagai kemasan primer kemudian plastik sebagai kemasan sekunder.

Pemasaran dodol IRT Pusaka dilakukan secara langsung di toko yang bertempat tidak jauh dari tempat produksi. Dodol IRT Pusaka memiliki rasa yang khas dan banyak digemari oleh konsumen, namun kelemahan dari produk yang ditawarkan pada konsumen adalah belum mencantumkan tanggal kadaluwarsa produk. Belum dicantumkan informasi tersebut karena belum adanya pengujian secara ilmiah untuk menghasilkan rekomendasi saran penyimpanan produk maupun batas tanggal masa penyimpanan yang baik untuk dikonsumsi.

Umur simpan adalah waktu hingga produk mengalami suatu tingkat degradasi mutu tertentu sehingga tidak layak dikonsumsi atau tidak lagi sesuai dengan kriteria yang tertera pada kemasannya (mutu tidak sesuai lagi dengan tingkatan mutu yang dijanjikan). Informasi umur simpan produk merupakan informasi yang wajib dicantumkan oleh produsen pada label kemasan produk pangan. Umur simpan produk pangan berkaitan dengan keamanan produk pangan dan memberikan jaminan mutu pada saat produk sampai ke tangan konsumen (Herawati, 2008).

Penentuan umur simpan produk pangan dapat dilakukan dengan menyimpan produk pada kondisi penyimpanan yang sebenarnya hingga produk tersebut mengalami kerusakan maksimal atau sering disebut dengan Extended Storage Studies (ESS). Cara tersebut dapat menghasilkan hasil yang tepat dan akurat, namun biasanya memerlukan waktu yang lama dan biaya yang besar. Pendugaan umur simpan pada produk juga dapat dilakukan dengan metode Accelerated Shelf Life Testing (ASLT) yaitu dengan penyimpanan produk pangan pada lingkungan yang menyebabkan terjadinya kerusakan dengan cepat, baik pada kondisi suhu atau kelembaban ruang penyimpanan yang lebih tinggi dari pada kondisi sebenarnya (Kusnandar, 2010). Pada penelitian ini metode ASLT Model Arrhenius digunakan untuk menentukan prakiraan umur simpan dodol kacang merah IRT Pusaka.

\section{METODE}

\section{Waktu dan Tempat Penelitian}

Penelitian ini dilaksanakan di Laboratorium Pengolahan Hasil Pertanian dan Laboratorium Pengawasan Mutu Program Studi Pendidikan Teknologi Agroindustri, Fakultas Pendidikan Teknologi dan Kejuruan UPI Bandung. Kegiatan Penelitian ini dilaksanakan bulan Februari hingga April tahun 2019.

\section{Alat dan Bahan}

Alat-alat yang digunakan selama penelitian ini yaitu neraca analitik, erlenmeyer, beaker glass, cawan petri, gelas ukur, tabung reaksi dan rak, inkubator, autoclav, pipet, alumunium foil, sudip, hand refraktometer dan kapas. Bahan yang digunakan selama penelitian ini yaitu sampel produk dodol kacang merah yang diproduksi oleh IRT Pusaka Cililin, aquades, $\mathrm{NaCl}$, media Potato Dextrose Agar (PDA) dan alcohol. 


\section{Rancangan Penelitian}

Penelitian ini menggunakan metode Accelerated Shelf Life Testing (ASLT) menggunakan persamaan Arrhenius. Dua faktor pengamatan yang dilakukan selama pengujian yaitu suhu penyimpanan dan waktu penyimpanan. Faktor suhu penyimpanan (S) terdiri dari dua taraf, yaitu $\mathrm{S} 1\left(25^{\circ} \mathrm{C}\right)$ dan $\mathrm{S} 2\left(35^{\circ} \mathrm{C}\right)$. Faktor waktu penyimpanan (W) terdiri dari enam taraf, yaitu w1 (hari ke-0), w2 (hari ke-3), w3 (hari ke-6), w4 (hari ke-9), w5 (hari ke-12), dan w6 (hari ke-15).

\section{Rancangan Analisis}

Data hasil pengukuran parameter mutu dengan dua faktor penyimpanan kemudian dianalisis menggunakan persamaan regresi linier berikut:

$$
Y=a+b x
$$

dimana:

$\mathrm{Y}=$ nilai analisis

a $=$ intercept

$\mathrm{b} \quad=$ konstanta penurunan mutu $=\mathrm{k}$

$\mathrm{x} \quad=$ waktu penyimpanan (hari)

Penggunaan regresi linier akan memperoleh koefisien determinasi $(r)$. Setiap nilai b yang diperoleh merupakan konstanta penurunan mutu setiap suhu penyimpanan. Selanjutnya nilai $k$ ditetapkan dalam rumus Arrhenius yaitu:

$$
\mathrm{k}=\mathrm{ko} \cdot \mathrm{e}^{-\mathrm{E}(\mathrm{R} / \mathrm{T})} \text { atau } \ln \mathrm{k}=\ln \mathrm{ko}-\mathrm{E} / \mathrm{RT}
$$

Keterangan:

$\mathrm{k} \quad=$ konstanta penurunan mutu

ko = konstanta (tidak tergantung suhu)

$\mathrm{E} \quad=$ energi aktivasi

$\mathrm{T} \quad=$ suhu mutlak $\left(273+{ }^{\circ} \mathrm{C}\right)$

$\mathrm{R}=$ konstanta gas $(1,986 \mathrm{kal} / \mathrm{mol})$

Karena In $\mathrm{k}$ dan -E/RT merupakan bilangan konstanta maka persamaan tersebut dapat dituliskan sebagai berikut:

$$
\text { In } \mathrm{k}=\mathrm{A}+\mathrm{B} \times 1 / \mathrm{T}
$$

Sehingga apabila setiap nilai $k$ dan $1 / T$ diplotkan dalam sebuah grafik, maka akan diperoleh gambar sebagai berikut:

In $\mathrm{k}$

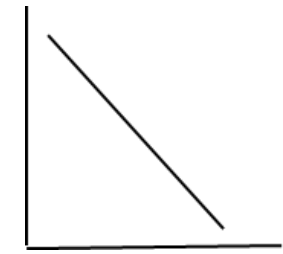

$1 / \mathrm{T}$

Setelah nilai $k$ dan $1 / T$ diplotkan dalam sebuah grafk, nilai $E$ dapat diperoleh sebagai berikut:

$$
\begin{aligned}
& -E / R=B \\
& \ln k o=A
\end{aligned}
$$

Jika telah diketahui besarnya penurunan mutu $(k)$ tersebut, maka dihitung umur simpan mengunakan persamaan sebagai berikut:

Persamaan kinetika untuk ordo nol $(n=0)$ : ts $=(A t-A o) / k$

Persamaan reaksi untuk orde satu $(n=1): t s=[(\ln A o / l n A t)] / k$

Keterangan:

Ao = mutu awal

At = mutu akhir (mutu produk yang tidak layak konsumsi)

$\mathrm{k}=$ konstanta penurunan mutu

ts = waktu kadaluarsa 


\section{Prosedur Penelitian}

Tahapan penelitian yang dilakukan untuk menentukan umur simpan dodol meliputi pengambilan sampel dodol kacang merah yang baru diproduksi oleh IRT Pusaka dan pengujian parameter mutu sampel dodol untuk memperoleh hasil pendugaan umur simpannya (Gambar 2). Parameter mutu yang diamati dalam penelitian ini adalah jumlah kapang dengan menggunakan pengujian Total Plate Count (TPC) dan analisis kadar gula dengan alat hand refraktometer.

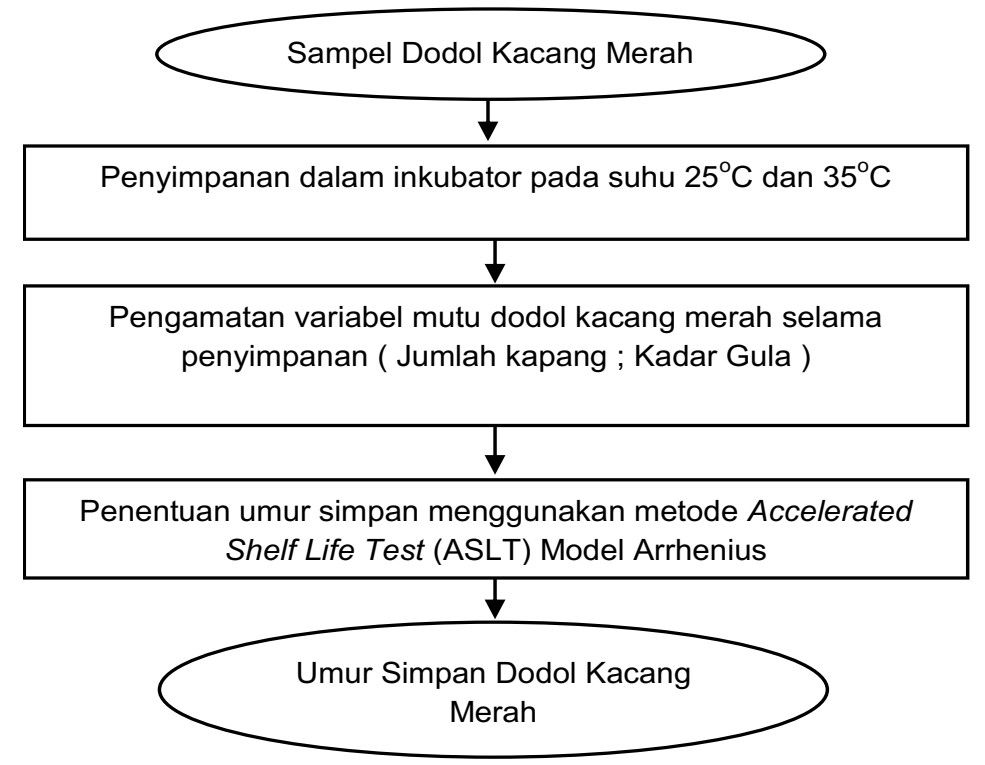

Gambar 2. Diagram Alir Penelitian

\section{HASIL DAN PEMBAHASAN \\ Jumlah Kapang}

Aspek mikrobiologi mempunyai perananan sangat penting dalam penilaian mutu produk pangan karena pada beberapa jenis produk pangan cepat mengalami penurunan mutu. Menurut Hanifah (2016) kerusakan bahan pagan oleh jasad renik dapat menyebabkan makanan atau minuman tidak layak konsumsi akibat penurunan mutu. Penurunan mutu bahan pangan dan hasil pertanian lainnya antara lain penurunan nilai gizi, penyimpangan warna, perubahan rasa dan bau. Suhu merupakan salah satu faktor yang mempengaruhi pertumbuhan mikroorganisme. Hasil pengamatan berdasarkan jumlah kapang menggunakan metode TPC selama penyimpanan dodol kacang merah yang disimpan pada suhu $25^{\circ} \mathrm{C}$ dan $35^{\circ} \mathrm{C}$ selama 15 hari dapat dilihat pada Tabel 1.

Tabel 1. Hasil Pengamatan Jumlah Kapang Dodol Kacang Merah

\begin{tabular}{|c|c|c|}
\hline Lama Penyimpanan (Hari) & \multicolumn{2}{|c|}{ Jumlah Kapang (koloni/g) } \\
\hline W1 (0) & $3 \times 10^{4}$ & $3 \times 10^{4}$ \\
\hline W2 (3) & $3 \times 10^{4}$ & $6 \times 10^{4}$ \\
\hline W3 (6) & $5 \times 10^{4}$ & $5 \times 10^{4}$ \\
\hline W4 (9) & $6 \times 10^{4}$ & $7 \times 10^{4}$ \\
\hline W5 (12) & $14 \times 10^{4}$ & $13 \times 10^{4}$ \\
\hline W6 (15) & $16 \times 10^{4}$ & $18 \times 10^{4}$ \\
\hline
\end{tabular}

Berdasarkan hasil analisis yang dilakukan, dapat diketahui bahwa semakin lama penyimpanan maka terjadi peningkatan jumlah koloni kapang. Hasil analisis jumlah kapang tersebut kemudian akan diplotkan ke dalam persamaan kinetika ordo nol dan ordo satu untuk menentukkan persamaan yang digunakan dalam menghitung umur simpan produk dodol. Laju perubahan jumlah kapang pada ordo nol dan ordo satu dapat dilihat berturut-turut pada Gambar 3. dan Gambar 4. 


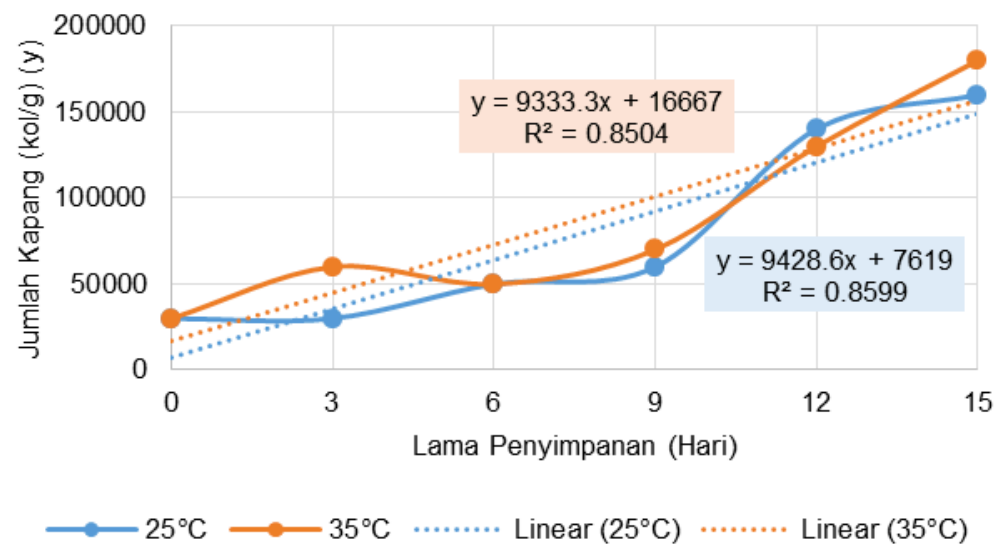

Gambar 3. Laju Perubahan Jumlah Kapang Ordo Nol

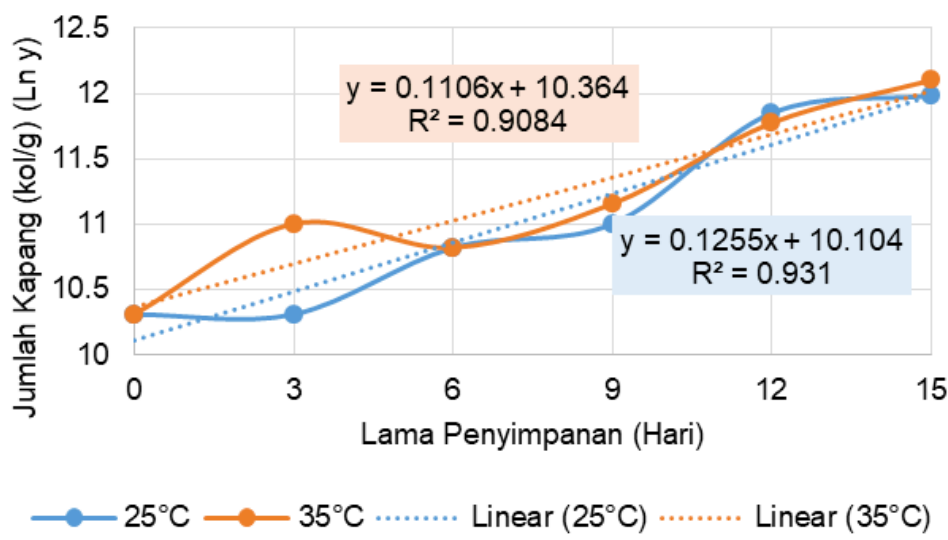

Gambar 4. Laju Perubahan Jumlah Kapang Ordo Satu

Berdasarkan grafik laju perubahan jumlah kapang dapat diketahui nilai koefisien determinasi $\left(R^{2}\right)$ pada ordo nol dan ordo satu. Untuk menentukan persamaan yang akan digunakan dalam menentukan perhitungan umur simpan maka dipilih berdasarkan nilai $R^{2}$ yang paling besar. Nilai $R^{2}$ berdasarkan jumlah kapang dapat dilihat pada Tabel 2.

Tabel 2. Nilai $R^{2}$ Jumlah Kapang

\begin{tabular}{ccc}
\hline \multirow{2}{*}{ Suhu $\left({ }^{\circ} \mathrm{C}\right)$} & \multicolumn{2}{c}{ Nilai $\mathrm{R}^{2}$ (R Square) } \\
& Ordo 0 & Ordo 1 \\
\hline 25 & $\mathrm{R}^{2}=0.8599$ & $\mathrm{R}^{2}=0.9310$ \\
35 & $\mathrm{R}^{2}=0.8504$ & $\mathrm{R}^{2}=0.9084$ \\
\hline
\end{tabular}

Berdasarkan data pada Tabel 2, dapat disimpulkan bahwa nilai $\mathrm{R}^{2}$ pada ordo satu lebih besar dibandingkan dengan nilai $\mathrm{R}^{2}$ ordo nol, sehingga pendugaan umur simpan dodol kacang merah bedasarkan jumlah kapang menggunakan ordo satu. Menurut Wulandari (2014) penurunan mutu yang mengikuti orde nol merupakan penurunan mutu yang bersifat konstan. Tipe kerusakan ini meliputi reaksi kerusakan enzimatik, pencoklatan enzimatik, dan reaksi oksidasi. Tipe kerusakan produk yang mengikuti orde reaksi satu meliputi ketengikan, pertumbuhan mikroba, offflavor, kerusakan vitamin, dan penurunan mutu vitamin. Setelah menentukan ordo yang digunakan yaitu menggunakan ordo satu, kemudian mendapatkan nilai In $\mathrm{k}$ yang akan diplotkan ke dalam grafik hubungan antara nilai In $\mathrm{k}$ dan 1/T. Grafik hubungan In $\mathrm{k}$ dan 1/T dapat dilihat pada Gambar 5. 


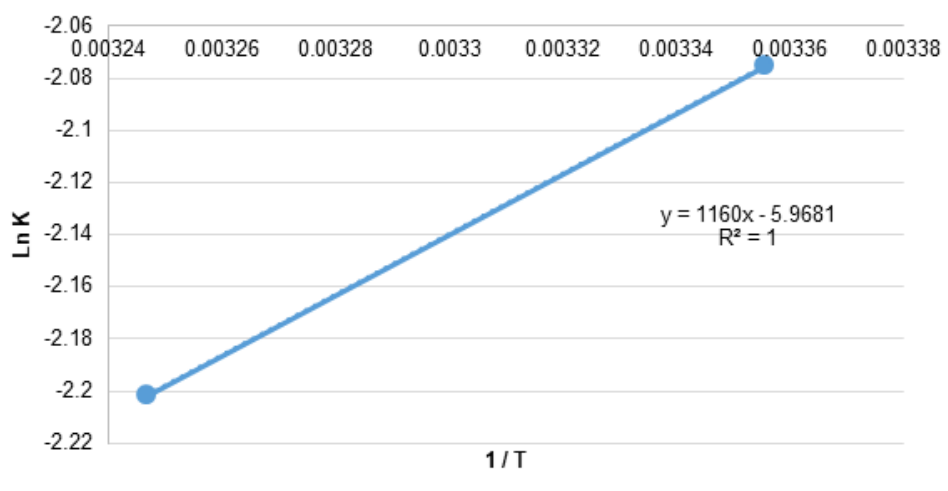

Gambar 5. Grafik Hubungan In k dan 1/T Jumlah Kapang

Berasarkan grafik hubungan antara nilai In $\mathrm{k}$ dan 1/T didapatkan persamaan regresi linier untuk mendapatkan nilai In $\mathrm{k} 0, \mathrm{Ea} / \mathrm{R}$ dan energi aktivasi (Ea). Persamaan regresi linier dari plot In $\mathrm{k}$ dan $1 / T$ pada perubahan jumlah kapang dodol kacang merah yaitu: $y=1160 x+5.9681$ dengan $R^{2}$ $=1$. Persamaan tersebut menghasilkan energi aktivasi sebesar $2303.76 \mathrm{kal} / \mathrm{mol}$. Kemudian menentukan konstanta penurunan mutu $(k)$ dari nilai In $k$ dan $E a / R$ yang diplotkan ke dalam persamaan Arhenius. Setelah didapatkan nilai konstanta penurunan mutu dodol kacang merah, maka dapat dihitung umur simpan dodol kacang merah pada masing-masing suhu. Hasil pendugaan umur simpan berdasarkan jumlah kapang dapat dilihat pada Tabel 3.

Tabel 3. Hasil Pendugaan Umur Simpan Berdasarkan Jumlah Kapang

\begin{tabular}{ccc}
\hline $\mathbf{T}\left({ }^{\circ} \mathbf{C}\right)$ & Konstanta Penurunan Mutu (k) & Ts (hari) \\
\hline 25 & 0.125495855 & 14.27744 \\
35 & 0.110596567 & 16.20086 \\
\hline
\end{tabular}

Umur simpan dodol kacang merah yang disimpan pada suhu $25^{\circ} \mathrm{C}$ adalah 14,27 hari, sedangkan umur simpan dodol kacang merah yang disimpan pada suhu $35^{\circ} \mathrm{C}$ adalah selama 16,20 hari. Hasil penelitian pendugaan umur simpan dodol kacang merah menunjukkan bahwa berdasarkan parameter jumlah kapang umur simpan dodol kacang merah yang disimpan pada suhu $35^{\circ} \mathrm{C}$ memiliki umur simpan lebih panjang. Hal tersebut dapat terjadi dikarenakan kadar air dodol yang disimpan pada suhu $35^{\circ} \mathrm{C}$ menguap lebih banyak dibandingkan dengan dodol yang disimpan pada suhu $25^{\circ} \mathrm{C}$. Kadar air berhubungan dengan aktivitas air (aw) dimana menurut Nurmanto (2004) semakin tinggi kadar air maka semakin tinggi pula nilai awnya. Suhu penyimpanan berpengaruh terhadap pertumbuhan mikroorganisme. Penyimpanan pada suhu tinggi mengakibatkan peningkatan jumlah air bebas terhambat sehingga kapang yang tumbuh pada dodol menjadi lebih sedikit.

Dodol yang rusak ditandai dengan munculnya hifa pada permukaan dodol. Kapang jenis Aspergillus merupakan penyebab kerusakan pada makanan, $A$. repens merupakan kapang yang tumbuh baik pada substrat dengan konsentrasi gula dan garam tinggi (Fardiaz, 1992). Berdasarkan SNI 01-2986-1992 mengenai dodol (BSN, 1992), kandungan kapang dalam dodol tidak boleh ada. Batas maksimum angka cemaran lempeng total pada SNI dodol tidak dicantumkan namun bila membandingkan dengan sandar dodol buah pada SNI Dodol nangka, dodol nenas dan dodol sirsak yang menunjukkan maksimum kandungan angka lempeng total sebesar $5 \times 10^{2}$ (BSN, 1996), maka kandungan mikroba pada dodol kacang merah telah melebihi batas maksimum dalam SNI sejak hari pertama dodol kacang merah disimpan. Adanya kandungan jumlah kapang selama pengujian dimungkinkan karena terdapat faktor yang memungkinkan terjadinya kontaminasi selama penyimpanan maupun kondisi selama proses pembuatan dodol seperti pencucian dan penggunaan alat, atau kebersihan kemasan. Kemasan primer yang digunakan pada dodol kacang merah yaitu kulit jagung. Kondisi kebersihan kulit jagung yang tidak baik dapat menjadi penyebab kontaminasi mikroba pada dodol kacang merah. 


\section{Kadar Gula}

Berdasarkan hasil pengukuran kadar gula selama penyimpanan dodol kacang merah pada suhu $25^{\circ} \mathrm{C}$ dan $35^{\circ} \mathrm{C}$, dapat diketahui bahwa jumlah kadar gula dodol kacang merah mengalami penurunan seiring dengan lamanya penyimpanan. Hasil analisis kadar gula kemudian diplotkan ke dalam persamaan kinetika ordo nol dan ordo satu untuk menentukkan persamaan yang digunakan dalam menghitung umur simpan produk dodol. Laju perubahan kadar gula pada ordo nol dan ordo satu dapat dilihat berturut-turut pada Gambar 6 dan Gambar 7.

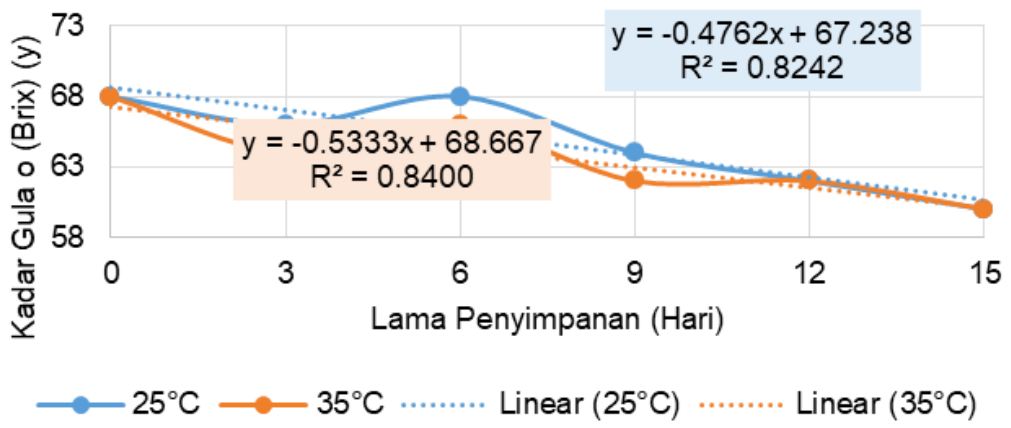

Gambar 6. Laju Perubahan Kadar Gula Ordo Nol

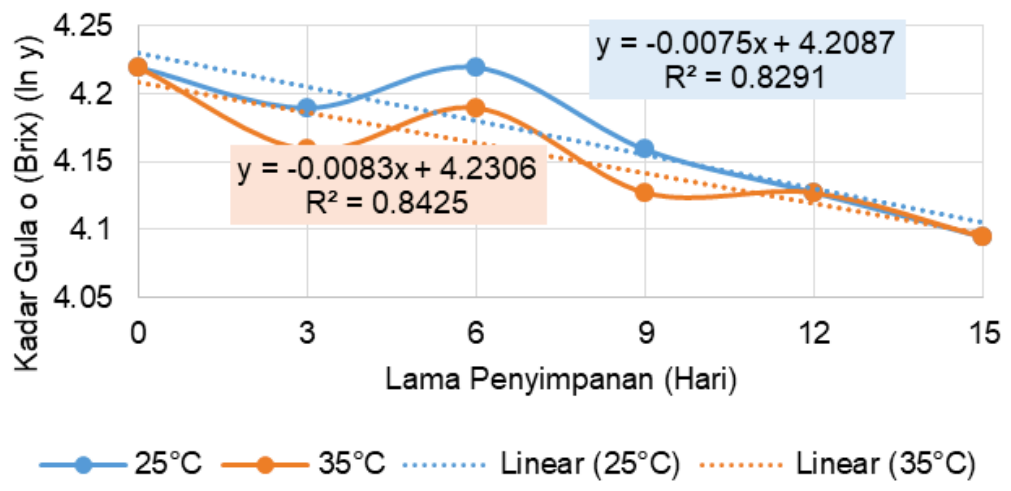

Gambar 7. Laju Perubahan Kadar Gula Ordo Satu

Berdasarkan grafik laju perubahan jumlah kapang dapat diketahui nilai koefisien determinasi $\left(R^{2}\right)$ pada ordo nol dan ordo satu. Untuk menentukan persamaan yang akan digunakan dalam menentukan perhitungan umur simpan maka dipilih berdasarkan nilai $\mathrm{R}^{2}$ yang paling besar. Nilai $R^{2}$ berdasarkan jumlah kapang dapat dilihat pada Tabel 4.

Tabel 4. Nilai $R^{2}$ Kadar Gula

\begin{tabular}{ccc}
\hline \multirow{2}{*}{ Suhu $\left({ }^{\circ} \mathrm{C}\right)$} & \multicolumn{2}{c}{ Nilai R2 } \\
& Ordo 0 & Ordo 1 \\
\hline 25 & $\mathrm{R}^{2}=0.8242$ & $\mathrm{R}^{2}=0.8291$ \\
35 & $\mathrm{R}^{2}=0.8400$ & $\mathrm{R}^{2}=0.8425$ \\
\hline
\end{tabular}

Berdasarkan tabel di atas, dapat disimpulkan bahwa nilai $\mathrm{R}^{2}$ pada ordo satu lebih besar dibandingkan dengan nilai $R^{2}$ ordo nol, sehingga pendugaan umur simpan dodol kacang merah bedasarkan kadar gula menggunakan ordo satu. Penurunan mutu yang mengikuti orde nol merupakan penurunan mutu yang bersifat konstan. Tipe kerusakan ini meliputi reaksi kerusakan enzimatik, pencoklatan enzimatik, dan reaksi oksidasi. Tipe kerusakan produk yang mengikuti orde reaksi satu meliputi ketengikan, pertumbuhan mikroba, off-flavor, kerusakan vitamin, dan penurunan mutu vitamin (Wulandari, 2014). Setelah menentukan ordo yang digunakan yaitu menggunakan ordo satu, kemudian mendapatkan nilai In $\mathrm{k}$ yang akan diplotkan ke dalam grafik hubungan antara nilai In $\mathrm{k}$ dan $1 / \mathrm{T}$. Grafik hubungan In $\mathrm{k}$ dan $1 / \mathrm{T}$ kadar gula dapat dilihat pada Gambar 8. 


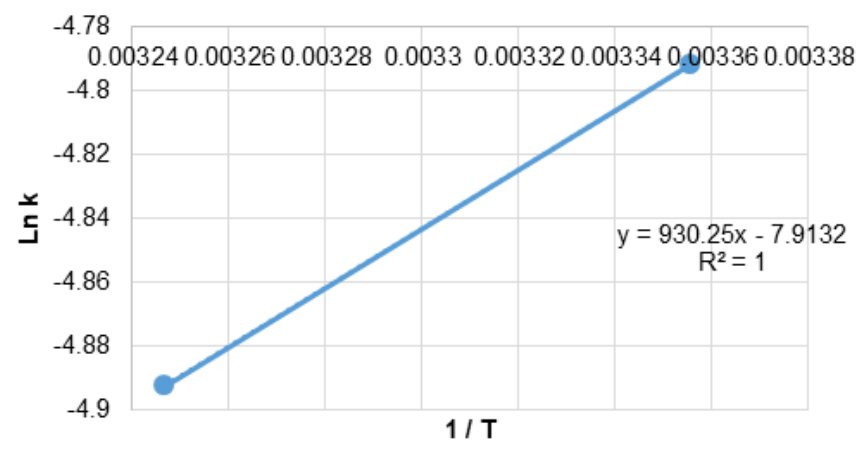

Gambar 8. Grafik Hubungan In k dan 1/T Kadar Gula

Berasarkan grafik hubungan antara nilai In $\mathrm{k}$ dan $1 / \mathrm{T}$ didapatkan persamaan regresi linier untuk mendapatkan nilai In $\mathrm{kO}, \mathrm{Ea} / \mathrm{R}$ dan energi aktivasi (Ea). Persamaan regresi linier dari plot $\ln \mathrm{k}$ dan $1 / T$ pada perubahan kadar gula dodol kacang merah yaitu: $y=930.25 x+7.9132$ dengan $R^{2}=$ 1. Persamaan tersebut menghasilkan energi aktivasi sebesar $1847.447 \mathrm{kal} / \mathrm{mol}$. Kemudian menentukan konstanta penurunan mutu (k) ditentukan dari nilai In $\mathrm{k}$ dan Ea/R yang diplotkan ke dalam persamaan Arhenius. Setelah didapatkan nilai konstanta penurunan mutu dodol kacang merah, maka dapat dihitung umur simpan dodol kacang merah pada masing-masing suhu. Hasil pendugaan umur simpan berdasarkan kadar gula dapat dilihat pada Tabel $\mathbf{5}$.

Tabel 5. Hasil Pendugaan Umur Simpan Berdasarkan Kadar Gula

\begin{tabular}{ccc}
\hline $\mathbf{T}\left({ }^{\circ} \mathbf{C}\right)$ & Konstanta Penurunan Mutu (k) & Ts (hari) \\
\hline 25 & 0.008299536 & 15.08074 \\
35 & 0.007499584 & 16.68935 \\
\hline
\end{tabular}

Umur simpan dodol kacang merah yang disimpan pada suhu $25^{\circ} \mathrm{C}$ adalah 15,08 hari, sedangkan umur simpan dodol kacang merah yang disimpan pada suhu $25^{\circ} \mathrm{C}$ adalah selama 16.68 hari. Hasil penelitian pendugaan umur simpan dodol kacang merah menunjukkan bahwa berdasarkan parameter kadar gula umur simpan dodol kacang merah yang disimpan pada suhu $35^{\circ} \mathrm{C}$ memiliki umur simpan lebih panjang. Hal tersebut dapat terjadi dikarenakan semakin tinggi suhu maka semakin berkurangnya kadar air. Menurut penelitian Manab (2007), kadar sukrosa berpengaruh sangat nyata terhadap kadar air dodol, semakin tinggi konsentrasi sukrosa terdapat kecenderungan peningkatan kadar air. Suhu penyimpanan berpengaruh terhadap penurunan kadar gula. Semakin tinggi suhu penyimpanan maka semakin berkurangnya kadar air yang menyebabkan semakin menurunnya kadar gula pada dodol.

Gula sebagai salah satu bahan baku pembuatan dodol berfungsi sebagai pemberi rasa manis dan sebagai bahan pengawet. Gula sebagai sukrosa yang digunakan dalam pembuatan dodol diperoleh dari gula pasir dan gula merah. Menurut Dewi (2018) penambahan gula pasir pada pemasakan nira yang biasa dilakukan oleh pengrajin gula mempengaruhi kadar sukrosa. Sukrosa terdiri dari monomer-monomer berupa glukosa dan fruktosa yang terikat oleh ikatan glikosidik. Gula pada konsentrasi yang tinggi dapat menghambat pertumbuhan mikroorganisme dan dapat menurunkan aktivitas air (Aw) bahan pangan (Buckle et al., 1987). Selama penyimpanan terjadi penurunan kadar gula pada dodol kacang merah. Menurut Buckle et al. (1987) penurunan mutu pangan juga dapat dipengaruhi oleh faktor pengemasan. Pengemasan memiliki peranan penting dalam mempertahankan mutu suatu produk pangan.

\section{KESIMPULAN}

Berdasarkan hasil penelitian yang dilakukan dapat disimpulkan bahwa:

1. Berdasarkan respon jumlah kapang, umur simpan dodol kacang merah yang disimpan pada suhu $25^{\circ} \mathrm{C}$ dan $35^{\circ} \mathrm{C}$ adalah 14.27 hari dan 16.20 hari.

2. Berdasarkan respon kadar gula, umur simpan dodol kacang merah yang disimpan pada suhu $25^{\circ} \mathrm{C}$ dan $35^{\circ} \mathrm{C}$ adalah 15.08 hari dan 16.68 hari. 


\section{DAFTAR PUSTAKA}

BSN. (1992). SNI 01-2986-1992- Syarat Mutu Dodol. Jakarta

BSN. (1996). SNI 01-4295-1996- Syarat Mutu Dodol Nangka. Jakarta

BSN. (1996). SNI 01-4296-1996- Syarat Mutu Dodol Nanas. Jakarta

BSN. (1996). SNI 01-4297-1996- Syarat Mutu Dodol Sirsak. Jakarta

Buckle K.A., R.A. Edward, G.H. Fleet, M. Wootton. (1987). IImu Pangan. Jakarta: Universitas Indonesia.

Dewi, A. R. (2018). Pendugaan Umur Simpan Gula Semut Aren Dengan Metode Arrhenius. Skripsi. Departemen Teknologi Industri Pertanian. Fakultas Teknologi Pertanian. Institut Pertanian Bogor.

Fardiaz, S. (1992). Mikrobiologi Pangan 1. Jakarta: Gramedia Pusaka Utama

Hanifah, R. (2016). Pendugaan Umur Simpan Dodol Tomat (Lycopersicum pyriforme) Menggunakan Metode Accelerated Shelf Life Testing (ASLT) Model Arrhenius. Jurnal. Program Studi Teknologi Pangan. Fakultas Teknik. Universitas Pasundan Bandung

Herawati, H. (2008). Penentuan Umur Simpan pada Produk Pangan. Balai Pengkajian Teknologi Pertanian, Jawa Tengah.

Kusnandar, F. (2010). Pendugaan Umur Simpan Metode ASLT. Departemen IImu Teknologi Pangan. IPB.

Manab, A. (2007). Kajian Pengunaan Sukrosa Terhadap Pencoklatan Non-enzimatis Dodol Susu. Jurnal Ternak Tropika Vol.6 No.2.

Nasaruddin N.L. Chin Y.A., Yusof. (2012). Effect of Processing on Instrumental Textural Properties of Raditional Dodol Using Back Extrusion. Int. Journal Food Pro. Vol. 15, No 3.

Syamsir, E. dan Prita D.L.S. (2010). Pengembangan Dodol Sebagai Produk Pangan Darurat. Jurnal Ilmu dan Teknologi Pangan. Vol 8 No.2.

Wulandari, R. (2014). Pengembangan dan Pendugaan Umur Simpan Minuman Sari Tebu dalam Kemasan Cup Menggunakan Metode Arrhenius. Jurnal. Institut Pertanian Bogor. 